\section{Hamman's syndrome accompanied by pneumorrhachis}

\section{Dear Editor,}

An 11-year-old male patient with asthma that was being treated sporadically presented with dyspnea and acute chest pain. He had no history of recent trauma. Physical examination showed that he was afebrile and tachypneic, with crackles on palpation of the chest, neck, and axillae. A chest X-ray showed pneumomediastinum, together with bilateral subcutaneous emphysema in the soft tissues of the chest and neck (Figures 1A and 1B), findings confirmed by computed tomography (CT) of the chest, which also showed intraspinal air in the posterior aspect of the spine (pneumorrhachis), as depicted in Figure 1C. At $72 \mathrm{~h}$ after admission, there was clinical improvement, with a reduction in the extent of the subcutaneous emphysema and significant resorption of the initial pneumomediastinum (Figure 1D). In view of those findings, the patient was diagnosed with Hamman's syndrome accompanied by pneumorrhachis.

Spontaneous pneumomediastinum, or Hamman's syndrome, is defined as free air in the mediastinum of no apparent cause, assuming that causes such as trauma, iatrogenic complications, and infections with gas-producing bacteria have been excluded $^{(1)}$. It is usually a benign, self-limiting condition that primarily affects men between 17 and 25 years of age, with an incidence of 1/30,000 hospital admissions ${ }^{(2)}$.

The pathophysiology of Hamman's syndrome is based on the Macklin effect, characterized by alveolar rupture caused by a pressure gradient between the alveoli and the pulmonary interstitium, with the consequent escape of air into the interstitium, the air then flowing toward the pulmonary hilum and mediastinum ${ }^{(3,4)}$.The main causes of spontaneous pneumomediastinum are intense physical exercise, the labor of childbirth, pulmonary barotrauma, deep dives, severe paroxysmal coughing, vomiting, asthma, a slender body type, the use of narcotics, and intense vocal effort ${ }^{(2)}$.

Clinical findings of Hamman's syndrome include chest pain, dyspnea, neck pain, and subcutaneous emphysema. One characteristic clinical sign, which can be detected on auscultation, is the presence of crackles synchronized with the beating of the heart, known as Hamman's sign or Hamman's crunch. Although Hamman's sign is highly suggestive of the condition, it is present in less than half of all cases ${ }^{(5)}$. The combination of Hamman's syndrome and pneumorrhachis is rare and is believed to be attributable to the passage of air through the posterior mediastinum to the neural foramina and epidural space ${ }^{(6,7)}$

Chest X-rays are still the gold standard for the diagnosis of Hamman's syndrome, with a sensitivity close to $100 \%$ if posteroanterior and lateral views are obtained ${ }^{(2)}$. The main findings include linear images of gas in the mediastinum, typically extending to the neck, together with blisters or large collections of air delineating the mediastinal blood vessels, upper airways, esophagus, or heart. In cases of clinical suspicion of Hamman's syndrome, CT can be performed if the chest X-ray findings are normal or inconclusive, because it allows the anatomical localization of the air in axial slices and subsequent reconstructions. CT is also the method of choice for the diagnosis and follow-up of pneumorrhachis ${ }^{(8)}$.

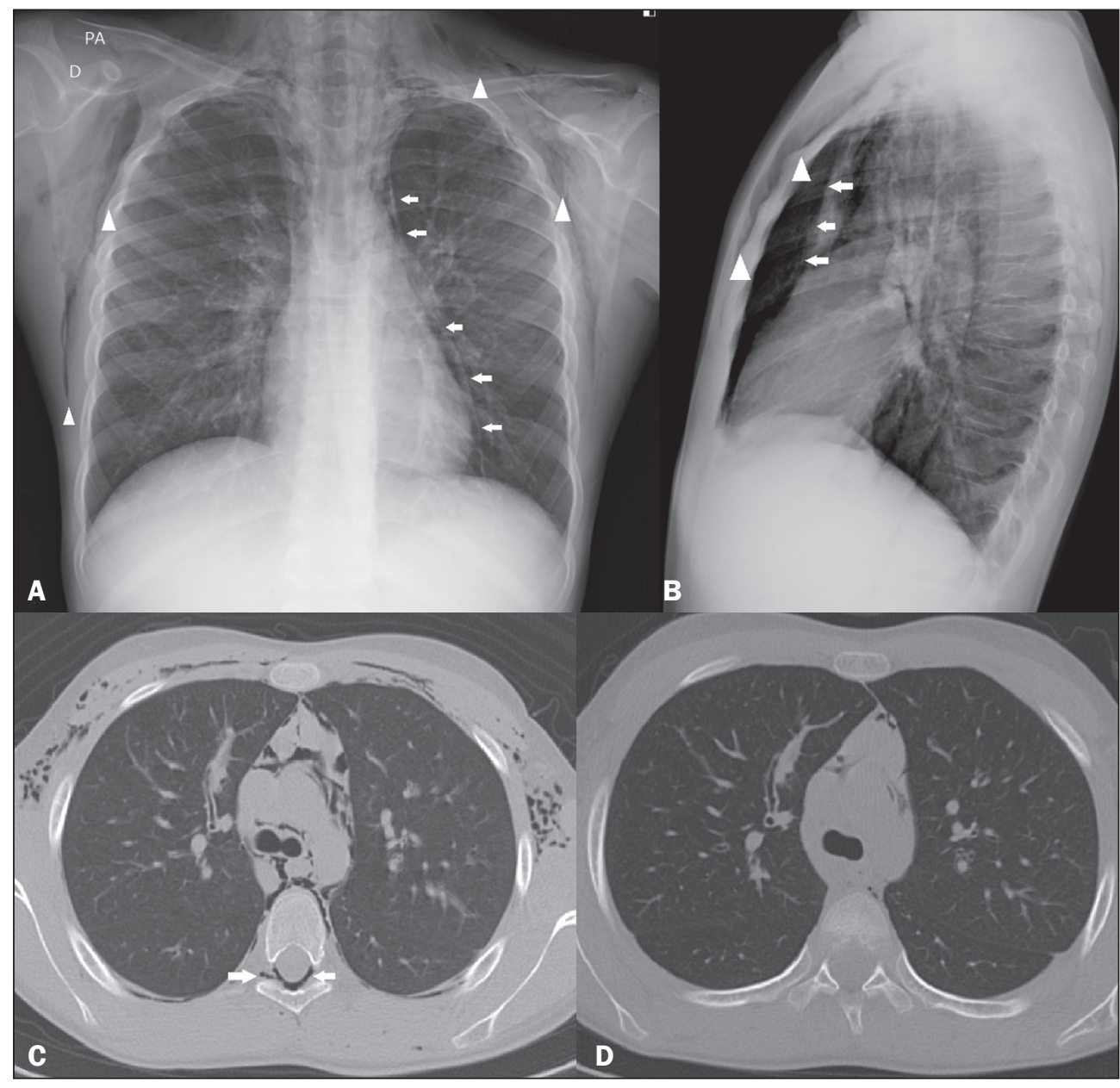

Figure 1. Chest $X$-rays, in posteroanterior and lateral views (A and B, respectively), showing pneumomediastinum (arrows) and soft tissue emphysema (arrowhead). The lateral view better identifies the air delineating the mediastinum anteriorly (arrows). CT with an intermediate window, slices at the level of the bronchial bifurcation being acquired at admission (C) and $72 \mathrm{~h}$ later (D), showing free air delineating the mediastinal structures, bronchi, and pulmonary vessels, as well as pneumorrhachis (arrow in C). Note the significant improvement of the pneumomediastinum, subcutaneous emphysema, and pneumorrhachis at $72 \mathrm{~h}$ after the initial CT (D). 
The standard treatment for Hamman's syndrome is clinical observation combined with supportive measures, usually in a hospital setting. The syndrome typically resolves spontaneously after two to seven days, and recurrence is uncommon ${ }^{(5)}$.

The prevalence of Hamman's syndrome is low. Nevertheless, it should be considered in the differential diagnosis of acute chest pain, especially in young patients with subcutaneous emphysema, and the possibility of pneumorrhachis should be investigated.

\section{REFERENCES}

1. Kelly S, Hughes S, Nixon S, et al. Spontaneous pneumomediastinum (Hamman's syndrome). The Surgeon. 2010;8:63-6.

2. Lopes FPL, Marchiori E, Zanetti G, et al. Spontaneous pneumomediastinum following vocal effort: a case report. Radiol Bras. 2010;43:137-9.

3. Murayama S, Gibo S. Spontaneous pneumomediastinum and Macklin effect: overview and appearance on computed tomography. World J Radiol. 2014;6:850-4.

4. Conti-de-Freitas LC, Mano JB, Ricz HMA, et al. A importância da suspeita clínica da síndrome de Hamman na sala de urgência. Rev Bras Cir Cabeça Pescoço. 2009;38:122-3.
5. Fatureto MC, Santos JPV, Goulart PEN, et al. Pneumomediastino espontâneo: asma. Rev Port Pneumol. 2008;14:437-41.

6. Alves GRT, Silva RVA, Corrêa JRM, et al. Pneumomediastino espontâneo (síndrome de Hamman). J Bras Pneumol. 2012;38:404-7.

7. Borem LMA, Stamoulis DNJ, Ramos AFM. A rare case of pneumorrhachis accompanying spontaneous pneumomediastinum. Radiol Bras. 2017;50:345-6.

8. Oertel MF, Korinth MC, Reinges MH, et al. Pathogenesis, diagnosis and management of pneumorrhachis. Eur Spine J. 2006;15 Suppl 5: $636-43$.

Andres Eduardo Cruz Guataqui ${ }^{1}$, Bernardo Carvalho Muniz ${ }^{2, a}$, Bruno Niemeyer de Freitas Ribeiro ${ }^{2, b}$, Luis Henrique Spielmann ${ }^{1}$, Miguel Angelo Milito ${ }^{1}$

1. Hospital Santa Teresa, Petrópolis, RJ, Brazil. 2. Instituto Estadual do Cérebro Paulo Niemeyer - Departamento de Radiologia, Rio de Janeiro, RJ, Brazil.

Correspondence: Dr. Bernardo Carvalho Muniz. Instituto Estadual do Cérebro Paulo Niemeyer - Departamento de Radiologia. Rua do Resende, 156, Centro. Rio de Janeiro, RJ, Brazil, 20231-092. Email: bernardocmuniz@yahoo.com.br.

a. https://orcid.org/0000-0003-1483-2759; b. https://orcid.org/0000-0002-1936-3026. Received 21 August 2017. Accepted after revision 22 September 2017.

http://dx.doi.org/10.1590/0100-3984.2017.0141

\section{$(\infty)) E Y$}

\section{Klippel-Feil syndrome accompanied by partial cleft of the cervical} spine: a not-so-unusual combination?

\section{Dear Editor,}

In this report, we present two cases within the spectrum of Klippel-Feil syndrome (KFS) accompanied by posterior partial division of the spinal cord. The first case was in a young woman who underwent magnetic resonance imaging (MRI) of the neck and chest for the investigation of hemivertebra and scoliosis. The MRI scan showed fusion and volumetric reduction of the C2-C5 vertebrae, accompanied by posterior cerebrospinal fluid cleft in the spinal column (Figure 1). The second case involved a adolescent male hospitalized for ventricular drain replacement and correction of hydrocephalus. MRI showed extensive fusion and deformity of the vertebrae throughout the cervical segment and in the initial portion of the thoracic segment, accompanied by posterior cerebrospinal fluid cleft extending from the bulb to the beginning of the thoracic segment (Figure 2).

KFS is characterized by the congenital fusion of two or more vertebral bodies, the cause of which remains uncertain. Etiological hypotheses include injury occurring at 3-8 weeks of gestation and an association with the genes that control the process of embryonic somite formation ${ }^{(1)}$. The classic clinical triad, as described by Maurice Klippel and André Feil, consists of shortening of the neck, giving the appearance of a low hairline at the back of the head, and a limited range of motion in the neck; the full triad is present in only $50 \%$ of cases $^{(2)}$. A wide range of cerebral and spinal malformations have been reported in patients with KFS, one of the most well documented being diastematomyelia, which is characterized by complete division of the neural tube and the formation of two hemicords separated by osseocartilaginous septum, typically in the lower thoracic and lumbar regions ${ }^{(3)}$. Among the few reported cases of KFS, spinal alterations occur in up to $50 \%$, posterior spinal cord cleft (also known as partial diastematomyelia) being one such alteration $^{(4-6)}$.

The relationship between vertebral fusion (KFS) and posterior partial spinal cord cleft is poorly documented, and the most plausible origin is related to the defects involving the alterations resulting from duplication of the notochord, which would explains in a more appropriate way the formation of diastematomyelia and the production of hemivertebrae or the so-called "butterfly" vertebrae ${ }^{(1)}$. One of the proposed mechanisms of vertebral fusion is extension of the cartilage formation process to
Figure 1. Case 1. A: Fusion of cervical vertebrae, extending from C2 to C5. B: Posterior division of the spinal cord.

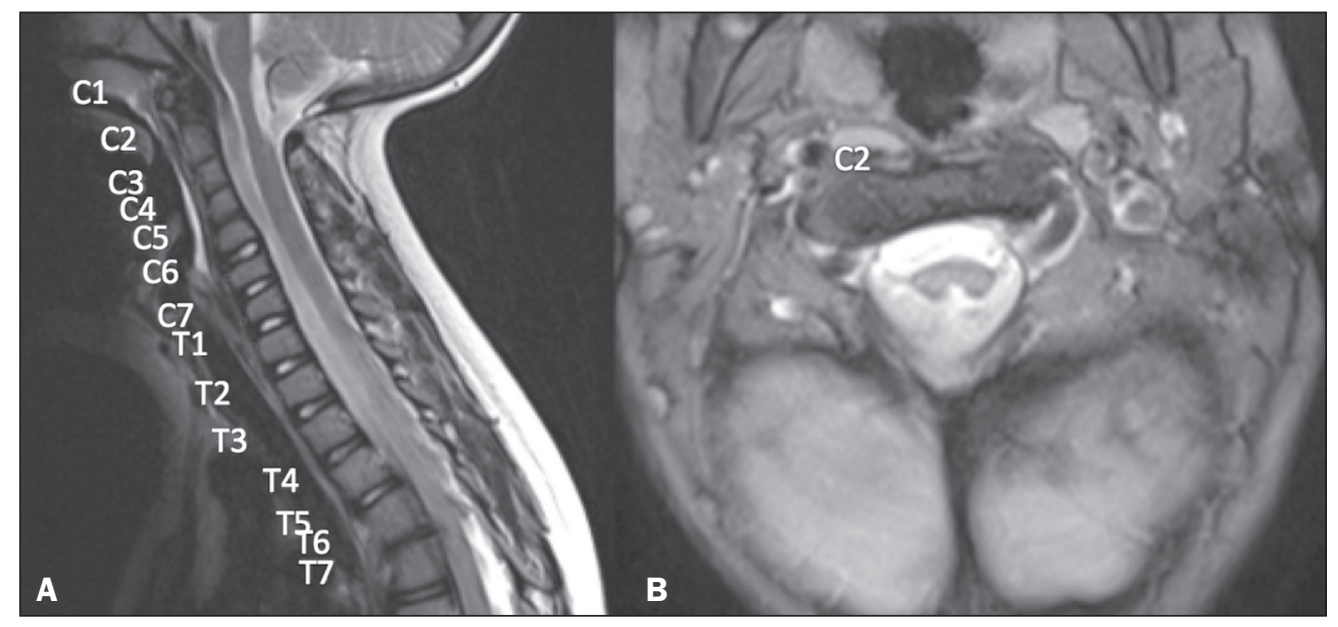

